\title{
Electrical Conductivity of Boron Oxide-Doped Yttria-Stabilized Cubic Zirconia (8YSZ)
}

\author{
B. $\operatorname{AKTAS}^{a, *}$ AND S. TEKELI ${ }^{b}$ \\ ${ }^{a}$ Harran University, Engineering Faculty, Mechanical Engineering Department, 63300, Sanliurfa, Turkey \\ ${ }^{b}$ Gazi University, Technology Faculty, Metallurgical and Materials Engineering Department, 06500, Ankara, Turkey
}

The effect of $\mathrm{B}_{2} \mathrm{O}_{3}$ addition on the electrical conductivity of $8 \mathrm{~mol} \%$ yttria-stabilized cubic zirconia (8YSZ) was investigated by analyzing the impedance spectra of $0-10$ wt. $\% \mathrm{~B}_{2} \mathrm{O}_{3}$-doped $8 \mathrm{YSZ}$ powders prepared via a colloidal process. The doped powders were then pelletized under a pressure of $200 \mathrm{MPa}$, and then sintered at $1400{ }^{\circ} \mathrm{C}$ for $10 \mathrm{~h}$. Measurements of the electrical conductivity of the sintered specimens within a frequency range of $100 \mathrm{mHz}-13 \mathrm{MHz}$, and temperature range of $300-800{ }^{\circ} \mathrm{C}$, revealed an increase in conductivity with increasing temperature. Furthermore, the grain interior, grain boundary and total conductivity of $8 Y$ SZ were found to be enhanced by the addition of 1 wt. $\% \mathrm{~B}_{2} \mathrm{O}_{3}$. This is attributed to the lattice distortion created by the addition of $\mathrm{B}^{3+}$ cations to the 8 YSZ lattice, which leads to an increase in the concentration of oxygen vacancies, thus ultimately resulting in an enhanced electrical conductivity.

DOI: $10.12693 /$ APhysPolA.127.1380

PACS: 81.05.Je, 81.20.Ev, 82.47.Ed

\section{Introduction}

The high ionic conductivity and good stability of yttria-stabilized cubic zirconia (8YSZ) has seen it widely used as an electrolyte material for solid oxide fuel cells (SOFCs), oxygen sensors, and thermal barriers. The addition of $\mathrm{Y}_{2} \mathrm{O}_{3}$ in solid solution helps to stabilize the fluorite structure of zirconia, thereby increasing its oxygen vacancy concentration. At high temperatures, however, the yttrium ions $(3+)$ are replaced by zirconium ions $(4+)$, creating many lattice vacancies in the process, in order to ensure electrical neutrality. These vacancies, in turn, provide a means for the transportation of oxygen ions through the material under an electrochemical potential at elevated temperatures [1, 2]. Accordingly, there have already been studies into the composition, structure, and conductivity of $8 \mathrm{YSZ}[3,4]$. In more recent years, the conductivity of $\mathrm{ZrO}_{2}$ doped with trivalent oxides, such as $\mathrm{Sc}_{2} \mathrm{O}_{3}, \mathrm{Yb}_{2} \mathrm{O}_{3}, \mathrm{Dy}_{2} \mathrm{O}_{3}$ and $\mathrm{Er}_{2} \mathrm{O}_{3}$, has been investigated with a view to further improving the ionic conductivity; these results indicating that such additives do indeed increase conductivity [5-7].

Boron oxide $\left(\mathrm{B}_{2} \mathrm{O}_{3}\right)$ formed by the thermal fusion of boric acid $\left(\mathrm{H}_{3} \mathrm{BO}_{3}\right)$ is amorphous in form, and represents an excellent network former. Moreover, boron oxides offer the advantage of a low coefficient of thermal expansion and high refractive index, and as such have been widely used in glass ceramics [8]. More recently, several researchers have investigated the effect of $\mathrm{B}_{2} \mathrm{O}_{3}$ addition on the electrical conductivity of ceramic materials. For instance, Tawichai et al. have studied its effect on $\mathrm{Li}_{1.5} \mathrm{Al}_{0.5} \mathrm{Ge}_{1.5}\left(\mathrm{PO}_{4}\right)_{3}$ glass ceramic, finding that the

* corresponding author; e-mail: baktas@harran.edu.tr conductivity is increased with the addition of $0.05 \mathrm{wt} . \%$ $\mathrm{B}_{2} \mathrm{O}_{3}[9]$. In another study, the phase transition and electrical properties of $\mathrm{Ba}\left(\mathrm{Ti}_{0.9} \mathrm{Sn}_{0.1}\right) \mathrm{O}_{3}$ ceramics with $\mathrm{B}_{2} \mathrm{O}_{3}$ added were investigated, and it was reported that the densification and dielectric properties were improved by the addition of a small amount of $\mathrm{B}_{2} \mathrm{O}_{3}[10]$.

With this in mind, the objective of this study is to determine the effect of $\mathrm{B}_{2} \mathrm{O}_{3}$ addition on the ionic conductivity of $8 \mathrm{YSZ}$ at low temperatures. The selection of $\mathrm{B}_{2} \mathrm{O}_{3}$ as a dopant for $8 \mathrm{YSZ}$ was based on the significant mismatch between the ionic radii of $\mathrm{ZrO}_{2}$ and $\mathrm{B}_{2} \mathrm{O}_{3}$, as well as the fact that their valences are nearly equal. We therefore herein present an analysis of the influence of $\mathrm{B}_{2} \mathrm{O}_{3}$ addition on the electrical conductivity and microstructure of $8 \mathrm{YSZ}$ through impedance spectroscopy and SEM, respectively.

\section{Experimental materials and procedure}

In this study, $0.3 \mu \mathrm{m}$ yttria-stabilized cubic zirconia (8YSZ) (Tosoh, Japan) and a $0.75 \mu \mathrm{m} \mathrm{B}_{2} \mathrm{O}_{3}$ powder (US Research Nanomaterials, Inc., USA) were used as the matrix material and additive, respectively.

Specimens for microstructural and electrical conductivity analysis were produced by means of colloidal processing. The subsequent doping process was carried out in a plastic container by mixing up to 10 wt. $\% \mathrm{~B}_{2} \mathrm{O}_{3}$ with 8 YSZ powder, zirconia balls, and ethanol. Mechanical mixing was performed using a "speks" type mixer at a speed of $200 \mathrm{rpm}$ for $12 \mathrm{~h}$, the resulting slurries being allowed to dry naturally by leaving the lid open for $24 \mathrm{~h}$. After drying, the agglomerated powders were ballmilled for $10 \mathrm{~min}$. in order to break up any agglomerates and obtain a good dispersion. These ball-milled powders were passed through a $60 \mu \mathrm{m}$ sieve, and then pelletized under a pressure of $200 \mathrm{MPa}$ using a single-axis die (radius $10 \mathrm{~mm}$, height $4 \mathrm{~mm}$ ). The inner surface of this steel 
die was cleaned after each pressing process, and stearic acid was applied to the sidewalls as a lubricant.

The pressed pellets were sintered in a box type furnace at $1400{ }^{\circ} \mathrm{C}$ for $10 \mathrm{~h}$ under normal atmospheric conditions, with a heating and cooling rate of $5^{\circ} \mathrm{C} / \mathrm{min}$. The surface of the sintered specimens was ground and polished using normal metallographic methods, and then thermally etched in the same furnace for $1 \mathrm{~h}$, at a temperature $50{ }^{\circ} \mathrm{C}$ below the sintering temperature. The microstructure of the sintered specimens was then analyzed using scanning electron microscopy (SEM, Jeol JSM-6060LV). The corresponding grain sizes were measured using the mean linear intercept method.

Electrical conductivity measurements were performed on sintered pellets measuring $10 \mathrm{~mm}$ in diameter and $3 \mathrm{~mm}$ in thickness. Both surfaces of these pellets were first slightly polished using abrasive paper, and then electrical connections were drawn by applying platinum paste to both surfaces. The specimens were all dried in an oven at $100{ }^{\circ} \mathrm{C}$ to eliminate any excess solvent, and then annealed at $800{ }^{\circ} \mathrm{C}$ for $30 \mathrm{~min}$ to prevent excessive shrinkage of the platinum electrodes. The temperature dependence of electrical conductivity was measured using a frequency response analyzer (Solartron, Model 1260) within a frequency range of $100 \mathrm{mHz}$ to $13 \mathrm{MHz}$. All measurements were performed in air, with the temperature ranging from 300 to $800{ }^{\circ} \mathrm{C}$ at intervals of $100{ }^{\circ} \mathrm{C}$. The AC impedance diagrams obtained were analyzed using ZView software.

\section{Results and discussion}

SEM micrographs of 8 YSZ in a pure state, and with added $\mathrm{B}_{2} \mathrm{O}_{3}$, are shown in Fig. 1. As can be seen from this, both the undoped and $\mathrm{B}_{2} \mathrm{O}_{3}$-doped $8 \mathrm{YSZ}$ samples have a coarse-grained microstructure, and coaxial polygonal grains (Fig. 1a-1d). More interesting, however, is the appearance of pores at the grain boundaries of $8 \mathrm{YSZ}$ at 5 and 10 wt. $\% \mathrm{~B}_{2} \mathrm{O}_{3}$ addition (Fig. $1 \mathrm{c}$ and $1 \mathrm{~d}$ ). Since it is known that $\mathrm{B}_{2} \mathrm{O}_{3}$ can be melted at a relatively low temperature $\left(\sim 450{ }^{\circ} \mathrm{C}\right)$, it is entirely possible that liquid-phase $\mathrm{B}_{2} \mathrm{O}_{3}$ may have formed at the grain boundaries [10]. If so, then this phase would have evaporated during sintering, the loss of $\mathrm{B}_{2} \mathrm{O}_{3}$ by evaporation providing an explanation for these grain boundary pores. Furthermore, an overdoping of $\mathrm{B}_{2} \mathrm{O}_{3}$ (5-10 wt.\%) would be expected to cause a higher porosity due to the formation of a glass phase at the grain boundaries. Using a mean linear intercept method, the grain sizes of the undoped and 1, 5, and $10 \mathrm{wt} . \% \mathrm{~B}_{2} \mathrm{O}_{3}$-doped 8YSZ samples, are found to be $3.11,2.8,3.73$, and $5.09 \mu \mathrm{m}$, respectively. Thus, increasing the $\mathrm{B}_{2} \mathrm{O}_{3}$ addition accelerates grain growth after sintering at $1400{ }^{\circ} \mathrm{C}$ for $10 \mathrm{~h}$, most likely due to the formation of a liquid phase during sintering. Similar grain growth with $\mathrm{B}_{2} \mathrm{O}_{3}$ addition has been reported in the literature for $\mathrm{BaTiO}_{3}$ and $\mathrm{Ba}_{0.7} \mathrm{Sr}_{0.3} \mathrm{TiO}_{3}$ ceramics, with high $\mathrm{B}_{2} \mathrm{O}_{3}$ additions causing grain growth with pores due to a precipitation mechanism in the liquid phase present during sintering $[11,12]$.
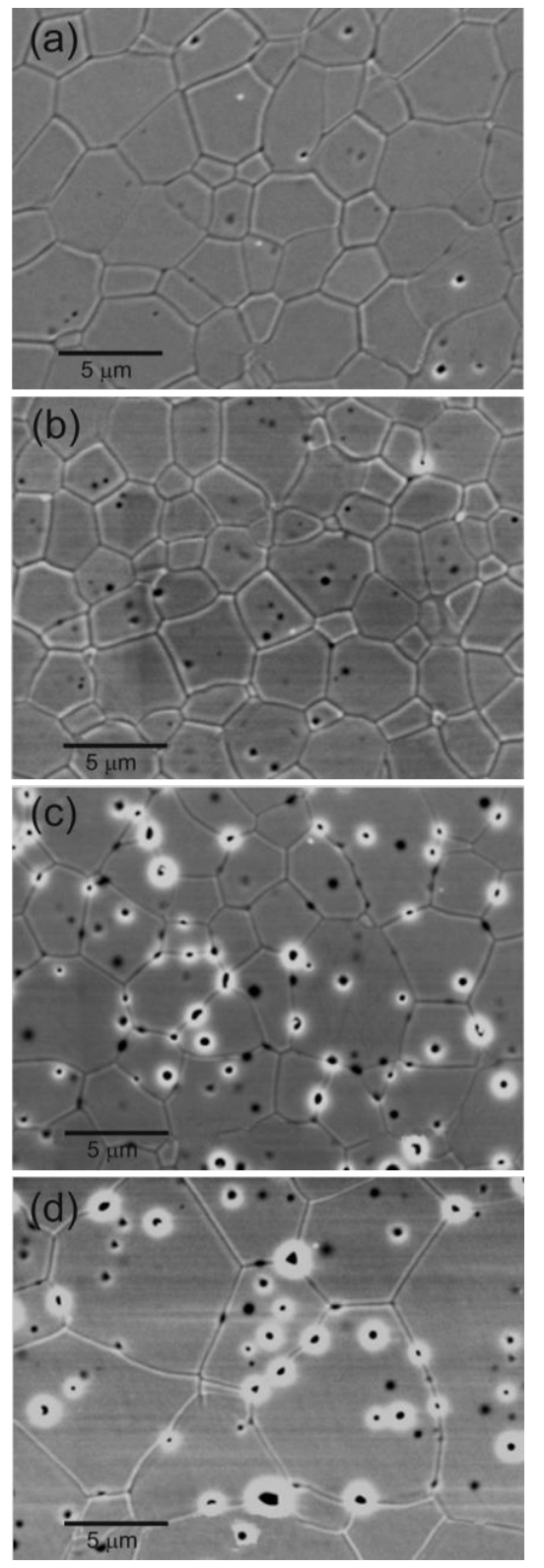

Fig. 1. SEM micrographs of $8 \mathrm{YSZ}$ specimens sintered at $1400{ }^{\circ} \mathrm{C}$ for $10 \mathrm{~h}$ with (a) 0 , (b) 1 , (c) 5, and (d) 10 wt. $\% \mathrm{~B}_{2} \mathrm{O}_{3}$ doping.

Figure 2 demonstrates the change in impedance for the grain interior and grain boundary as a function of dopant concentration. As can be seen from these curves, three arcs are clearly evident at a test temperature of $300{ }^{\circ} \mathrm{C}$ for both high and low frequencies (Fig. $2 \mathrm{a}-2 \mathrm{~d}$ ). The first and second of these arcs represents the grain interior and grain boundary resistance, respectively; while the sum of the two arcs gives the total resistance. Thus, the grain boundary resistance $\left(R_{g b}\right)$ of $8 \mathrm{YSZ}$ is clearly reduced by the addition of 1 wt. $\% \mathrm{~B}_{2} \mathrm{O}_{3}$, the lower value indicating the presence of an electrically conductive phase at the grain boundary. Furthermore, the grain interior resistance $\left(\mathrm{R}_{g i}\right)$ of a $1 \mathrm{wt} . \% \mathrm{~B}_{2} \mathrm{O}_{3}$-doped $8 \mathrm{YSZ}$ sample is 
also lower than that of undoped 8YSZ. The grain interior $\left(\sigma_{g i}\right)$ and grain boundary $\left(\sigma_{g b}\right)$ conductivities were calculated by the following equation:

$$
\sigma_{g i}=\frac{1}{R_{g i}} \frac{L}{A}, \quad \sigma_{g b}=\frac{1}{R_{g b}} \frac{L}{A},
$$

where $R_{g i}$ is the grain interior resistance, $R_{g b}$ is the grain boundary resistance, and $L$ and $A$ are the thickness and cross-sectional area of the specimen, respectively.
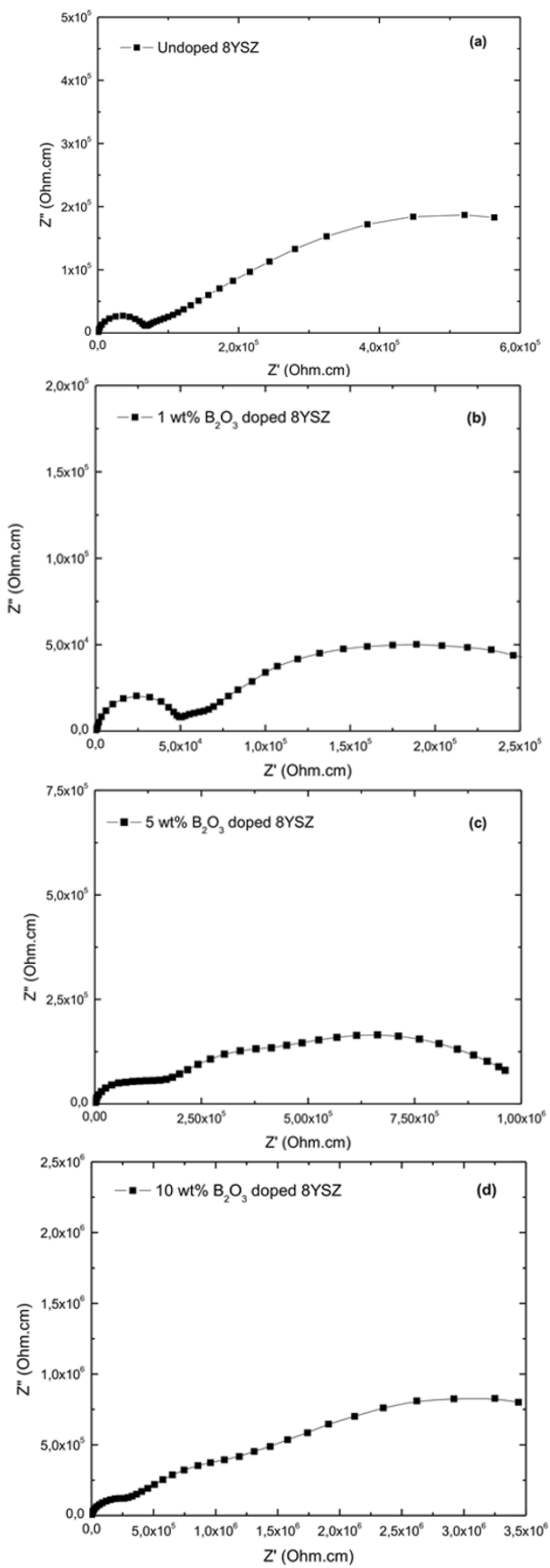

Fig. 2. AC impedance spectroscopy diagrams of 8YSZ specimens at $300{ }^{\circ} \mathrm{C}$ with (a) 0, (b) 1, (c) 5, and (d) 10 wt. $\% \mathrm{~B}_{2} \mathrm{O}_{3}$-doping.
The effect of $\mathrm{B}_{2} \mathrm{O}_{3}$ addition on the grain interior $\left(\sigma_{g i}\right)$ and grain boundary conductivity $\left(\sigma_{g b}\right)$ of $8 \mathrm{YSZ}$ at $300{ }^{\circ} \mathrm{C}$ is presented in Fig. 3. Here, both $\sigma_{g i}$ and $\sigma_{g b}$ are again increased with 1 wt. $\% \mathrm{~B}_{2} \mathrm{O}_{3}$ addition; the dissolved $\mathrm{B}^{3+}$ cations distorting the crystal lattice of $8 \mathrm{YSZ}$, thereby causing an increase in the concentration of oxygen vacancies that increases the grain interior, grain boundary and total conductivity. In principle, both di- and trivalent dopants are capable of introducing oxygen vacancies into a zirconia crystal lattice [13]. However, the addition of 5 and 10 wt. $\%$ of $\mathrm{B}_{2} \mathrm{O}_{3}$ is shown to actually reduce the grain interior, grain boundary, and total conductivity values at $300{ }^{\circ} \mathrm{C}$. It is possible that with increasing $\mathrm{B}_{2} \mathrm{O}_{3}$ content, the defects associated with oxygen vacancies clustered in the grain interior may reduce the mobility of oxygen ions. This decrease in conductivity may then result in the vacancies becoming more regular by interaction with defect pairs, thereby blocking each other. Thus, an improved ionic conductivity is only evident when a small amount of $\mathrm{B}_{2} \mathrm{O}_{3}$ is added (1 wt.\%), due to lattice distortion in the $8 \mathrm{YSZ}$, and the formation of a conductive secondary phase at the grain boundaries.

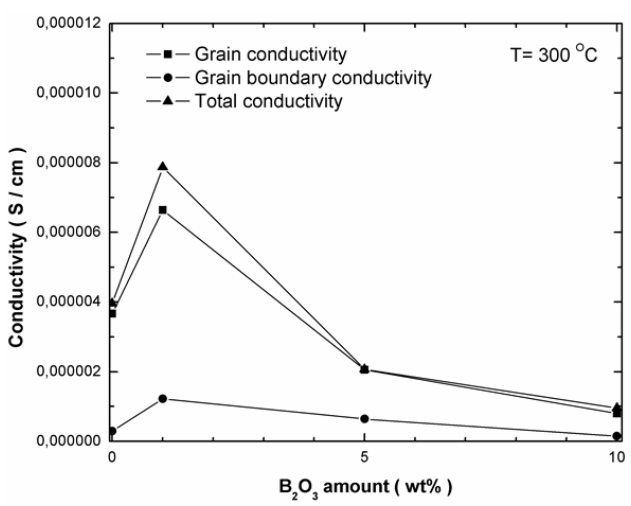

Fig. 3. The effect of $\mathrm{B}_{2} \mathrm{O}_{3}$ content on the conductivity of $8 \mathrm{YSZ}$ at $300{ }^{\circ} \mathrm{C}$.

The grain interior and grain boundary activation energies for undoped and $\mathrm{B}_{2} \mathrm{O}_{3}$ - doped $8 \mathrm{YSZ}$ samples were calculated using the Arrhenius equation:

$$
\sigma=\frac{\sigma_{0}}{T} \exp \left(-\frac{E_{a}}{k_{B} T}\right)
$$

where $T$ is the absolute temperature, $\sigma_{0}$ is a preexponential factor, and $E_{a}$ and $k_{B}$ are the activation energy and Boltzmann constant, respectively.

Figure 4 shows the grain interior and the grain boundary activation energies $\left(E_{a}\right)$ for the undoped and $\mathrm{B}_{2} \mathrm{O}_{3^{-}}$ doped $8 \mathrm{YSZ}$ samples. From this, the $E_{a}$ values of the undoped and 1, 5, and 10 wt. $\% \mathrm{~B}_{2} \mathrm{O}_{3}$-doped $8 \mathrm{YSZ}$ samples were calculated as 1.15, 1.07, 1.09 , and $1.13 \mathrm{eV}$, respectively (Fig. 4a). We can see from this, that the grain interior activation energy in $\mathrm{B}_{2} \mathrm{O}_{3}$-doped $8 \mathrm{YSZ}$ is lower than that of undoped $8 \mathrm{YSZ}$, suggesting that the transfer of ions in the grain interior is aided by a 1 wt. $\% \mathrm{~B}_{2} \mathrm{O}_{3}$ addition. The grain boundary activation energy for un- 

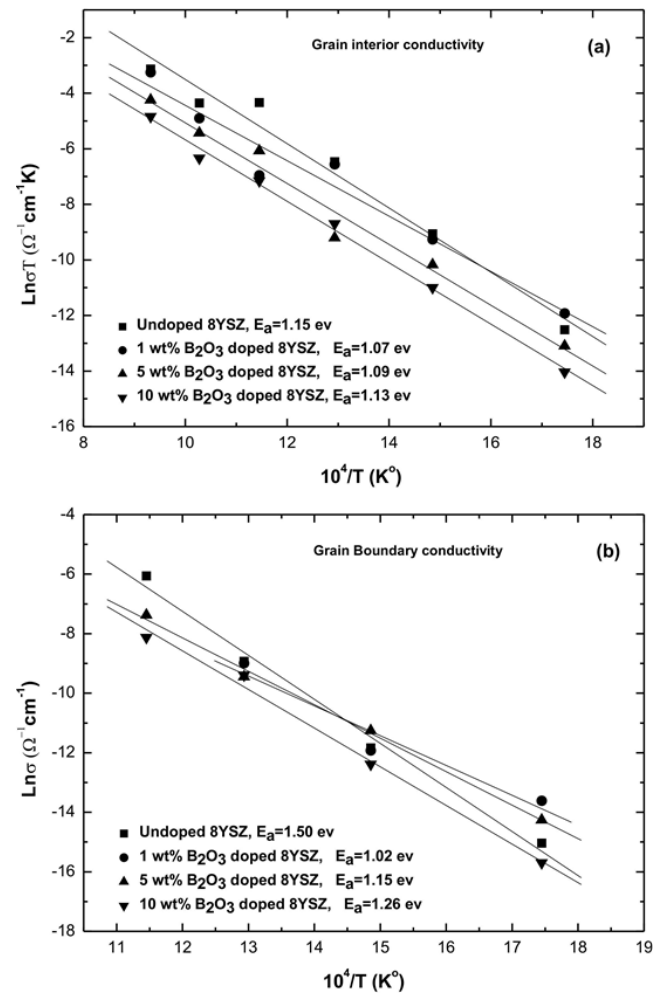

Fig. 4. Change in activation energies of undoped and $\mathrm{B}_{2} \mathrm{O}_{3}$-doped $8 \mathrm{YSZ}$ specimens for the (a) grain interior and (b) grain boundary conductivity.

doped $8 \mathrm{YSZ}$ was calculated as $1.50 \mathrm{eV}$; and for the 1, 5, and 10 wt. $\% \mathrm{~B}_{2} \mathrm{O}_{3}$-doped $8 \mathrm{YSZ}$ samples as $1.02,1.15$, and $1.26 \mathrm{eV}$, respectively (Fig. $4 \mathrm{~b}$ ). The lower values obtained for the $\mathrm{B}_{2} \mathrm{O}_{3}$-doped $8 \mathrm{YSZ}$ specimens mean that ion transfer at the grain boundary is indeed easier than that of undoped $8 \mathrm{YSZ}$, with the low grain boundary activation energy also indicative of an electrical conductor. This decrease in the grain boundary activation energy is attributable to the presence of $\mathrm{B}_{2} \mathrm{O}_{3}$ as a secondary phase at the grain boundaries and triple points of $8 \mathrm{YSZ}$, creating an increase in $\mathrm{B}^{3+}$ charge carrier ions with increasing temperature.

\section{Conclusions}

This study has shown that the addition of $\mathrm{B}_{2} \mathrm{O}_{3}$ to $8 \mathrm{YSZ}$ causes an increase in grain size after sintering due to the formation of a liquid phase at the grain boundaries. An increase observed in the grain interior and grain boundary conductivity of $8 \mathrm{YSZ}$ at $300{ }^{\circ} \mathrm{C}$ with the addition of 1 wt. $\% \mathrm{~B}_{2} \mathrm{O}_{3}$ is attributed to the lattice distortion caused by the addition of $\mathrm{B}^{3+}$ cations into the $8 \mathrm{YSZ}$ lattice. This leads to an increase in the concentration of oxygen vacancies in $8 \mathrm{YSZ}$, thus resulting in an enhancement of its electrical conductivity. On the basis of the activation energy results, the grain interior and grain boundary ion transport is clearly improved in the case of 1 wt. $\% \mathrm{~B}_{2} \mathrm{O}_{3}$-doped $8 \mathrm{YSZ}$, when compared with its undoped state, which is considered to be related to the increased oxygen vacancies. Thus, the grain interior and the grain boundary activation energy of $8 \mathrm{YSZ}$ is reduced by the addition of $1 \mathrm{wt} . \% \mathrm{~B}_{2} \mathrm{O}_{3}$.

\section{Acknowledgments}

This work has been supported by HUBAK (the scientific research projects commission of Harran University, Sanliurfa, TURKEY) under project number K14005. The authors are grateful to the scientific research projects commission of Harran University for financial support, and Gazi University for the provision of laboratory facilities.

\section{References}

[1] M.J. Verkerk, A.J.A. Winnubst, A.J. Burggraaf, J. Mater. Sci. 17, 3113 (1982).

[2] M. Miyayama, H. Yanagida, A. Asada, Am. Ceram Soc. Bull. 64, 660 (1985).

[3] B. Aktaş, High Temp. Mater. Proc. 32, 551 (2013).

[4] T.L. Wen, D. Wang, M. Chen, H. Tu, Z. Lu, Z. Zhang, H. Nie, W. Huang, Solid State Ionics 148, 513 (2002).

[5] Y. Li, J. Gong, Z. Tang, Z. Zhang, J. Chin. Ceram. Soc. 25, 705 (1997).

[6] Z. Lv, R. Guo, P. Yao, F. Dai, Mater. Des. 28, 1399 (2007).

[7] B. Aktas, S. Tekeli, M. Kucuktuvek, J. Mater. Eng. Perform. 23, 349 (2014).

[8] S. Koçyiğit, Ö. Gökmen, S. Temel, A. Aytimur, İ. Uslu, S.H. Bayari, Ceram. Int. 39, 7767 (2013).

[9] H.S. Jadhav, M.S. Cho, R.S. Kalubarme, J.S. Lee, K.N. Jung, K.H. Shin, C.J. Park, J. Power Sources 241, 502 (2013).

[10] N. Tawichai, U. Intatha, S. Eitssayeam, K. Pengpat, G. Rujijanagul, T. Tunkasiri, Phase Transit. 83, 55 (2010).

[11] H. Erkalfa, B. Yuksel, T.O. Ozkan, Key Eng. Mater. 264-268, 1333 (2004).

[12] S.M. Rhim, H. Bak, S. Hong, O.K. Kim, J. Am. Ceram. Soc. 83, 3009 (2000).

[13] M.B. Ricoult, M. Badding, Y. Thibault, Adv. El. Electroch. Ceram. 179, Wiley USA, pp. 173, 2012. 